\title{
Declaring War on Clostridium difficile and other GI Pathogens: A Review of Disposable Commode Products
}

\section{Molly Bridget Delaney}

Emergency Department Nurse Manager, East Bank University of Minnesota Medical Center, Fairview 425 Delaware Street SE Box 710 Minneapolis, Minnesota 55455, USA

*Corresponding author: Molly Delaney Emergency Department Nurse Manager, East Bank University of Minnesota Medical Center, Fairview 425 Delaware Street SE Box 710 Minneapolis, Minnesota 55455, USA, Tel: 612273 2977, Pager 612899 8332; Fax 612273 2910; E-mail: mdelane2@fairview.org

Received date: March 04, 2014, Accepted date: September 05, 2014, Publication date: September 08, 2014

Copyright: @ 2014 Delaney MB. This is an open-access article distributed under the terms of the Creative Commons Attribution License, which permits unrestricted use, distribution, and reproduction in any medium, provided the original author and source are credited.

\begin{abstract}
Albert Einstein defines insanity as doing the same thing over and over again and expecting different results. We have seen the evolution of disposable syringes, bedpans, suture trays and other equipment known to spread germs. However, bedside commode methods have not changed since the practice of Florence Nightingale. Yet, Clostridium difficile and other gastrointestinal pathogens add billions of dollars to United States health care costs annually. Perhaps it is time to reconsider current methods and equipment in bedside toileting
\end{abstract}

Keywords: Chain of infection; Bedside toileting; Commodes; Fecal pathogens

\section{Design}

A literature search of the chain of infection was performed to explore and define the current evolution of the current GI pathogen epidemic and how institutions are responding to growing virulence of microorganisms.(Figure 1).

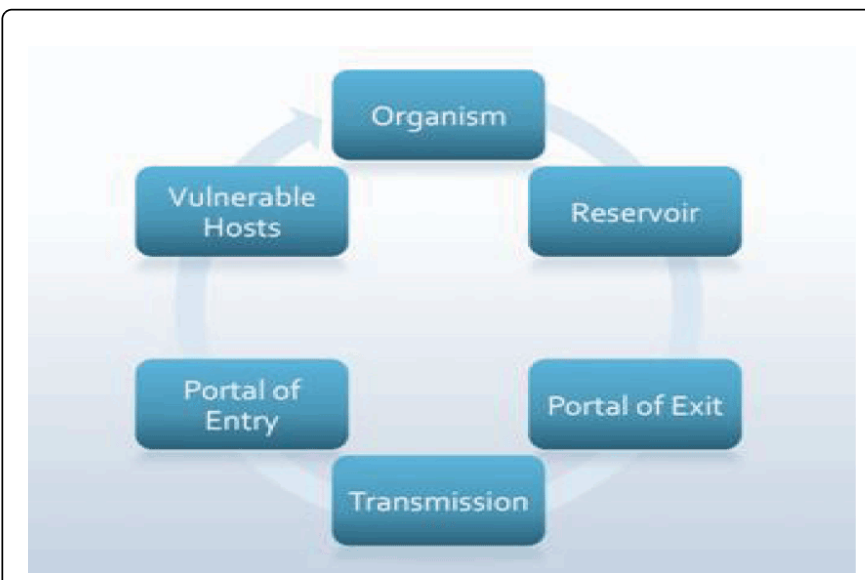

Figure 1: Chain of Infection.

- Organisms: C Diff, Salmonella, Shigella, E Coli, Rotavirus and Norovirus [1]. Clostridium Difficile and these gastrointestinal pathogens add billions of dollars to United States health care costs annually [2].

- Reservoirs: for GI germs are commode pails that staff reuse between patients. Thermal decontamination parameters for bedpans and commode pails ( $80 \mathrm{C}$ for 1 minute) are not adequate to eliminate $C$. difficile spores [3]. Therefore, cleaning methods have evolved to include sprays and wipes, which are tested on flat surfaces. However, flat surface tests do not reflect spore activity on non-flat surfaces, which are more commonly found in the health care environment [4]. Use of black lights after a 4-5 minute "clean" demonstrates this evidence. Inadequately cleaned equipment serves as a reservoir for pathogens.

- Portal of Exit: Health care institutions are a magnet for germs. Patients with debilitating diarrhea and dehydration are attracted to health care centers for fluids and antibiotics if indicated. Germs are shed with every movement of every visit.

- Transmission: Busy nursing staff may need to cut corners with 4-5 minute scrubs due to inadequate staffing or at-risk behaviors. Table 1 informs about the labor required for bedside toileting. Moreover, hand washing compliance rates ranged between $50-87 \%$ in a large urban hospital [5]. In addition, PPE use ranged from $5-83 \%$ for specialty nurses in contact with potentially infected material [6]. Hopper dependence compounds the issue when long distances sewage hauling results in splash injuries for employees and patients. Videos of the toilet and hopper flushing plumes on social media illustrate how germs are carried on staff uniforms and hair.

Time Spent Bedside Toileting (in Hours) Per 24 Hour Day

Unit / \% Patients Needing Bedside Toileting

\begin{tabular}{|l|l|l|l|l|l|l|l|}
\hline Occupied Beds & ICU/95 & Medical/85 & Surgical/80 & Rehab/95 & Neuro/95 & Nursing Home /95 & Hospice /80 \\
\hline
\end{tabular}




\begin{tabular}{|c|c|c|c|c|c|c|c|}
\hline 5 & 1.6 & 1.3 & 1.3 & 1.6 & 1.6 & 1.6 & 1.3 \\
\hline 10 & 3.2 & 2.7 & 2.7 & 3.2 & 3.2 & 3.2 & 2.7 \\
\hline 15 & 4.8 & 4.0 & 4.0 & 4.8 & 4.8 & 4.8 & 4.0 \\
\hline 20 & 6.3 & 5.3 & 5.3 & 6.3 & 6.3 & 6.3 & 5.3 \\
\hline 25 & 7.9 & 6.7 & 6.7 & 7.9 & 7.9 & 7.9 & 6.7 \\
\hline 30 & 9.5 & 8.0 & 8.0 & 9.5 & 9.5 & 9.5 & 8.0 \\
\hline 35 & 11.1 & 9.3 & 9.3 & 11.1 & 11.1 & 11.1 & 9.3 \\
\hline 40 & 12.7 & 10.7 & 10.7 & 12.7 & 12.7 & 12.7 & 10.7 \\
\hline \multicolumn{8}{|c|}{ Once cross indexed, multiply each by the average wage of person toileting } \\
\hline \multicolumn{8}{|c|}{ That is how much you are paying to clean commode buckets per day. } \\
\hline \multicolumn{8}{|c|}{$\begin{array}{l}\text { Assumptions: } \\
\text { - } 5 \text { minutes spent cleaning commode bucket before or after use. } \\
\text { - For each bed occupied by a patient needing bedside commode, there are } 4 \text { occurances per } 24 \text { hours. } \\
\text { - Horizontal percentages above are based on predicted toileting needs per unit type/acuity. }\end{array}$} \\
\hline
\end{tabular}

Table 1: Time spent by Nursing Staff for Bedside Toileting.

- Portals of Entry: are when contaminated employees or equipment share germs to patients with the next round of bedside toileting. Meanwhile, as Baby Boomers age and become chronically ill, the number of patients taking diuretics and bowel medications grows. This leads to more toileting events.

- Vulnerable Hosts: are anyone who is fatigued, sleep deprived, run down or functioning below their par. In addition, immunosuppressant drugs are now used in cancers, asthma, fibromyalgia, arthritis, transplantation, lupus, Tuberculosis, Multiple Sclerosis, Myasthenia Gravis, Crohns' and many other diseases. More populations are now at risk.

\section{Topic}

Needles, syringes, bedpans, suture trays and other equipment are disposable to prevent cross contamination. Extrapolation of research from these actions has brought forth a new industry in disposable commode equipment [7].

While basic commode liners do help eliminate hopper dependence, buckets must still be cleaned. Commode bags with diaper materials enable direct trash disposal. Compostable bags are available as well but there are costs involved. However, costs eliminated are macerator, sluice machines and washer disinfectors [8-10]. Sterile stores labor is increased with handling of disposables but that is cancelled out by elimination of handling and delivering machine washed equipment. Equipment breakdowns and on call costs go away for maintenance of cleaning equipment. Also eliminated is sewer snaking of wipes and flood clean-up costs from wiping clogs. Disposables enable folding commode chairs to be hung in each room, hallway or pod. Mounted dispensers can be in each room holding up to 4 at a time. All of the above eliminate walking to and from hoppers which prevents delays. These delays previously resulted in incontinence, skin integrity issues, linen changes and increased laundry costs (Figure 2)

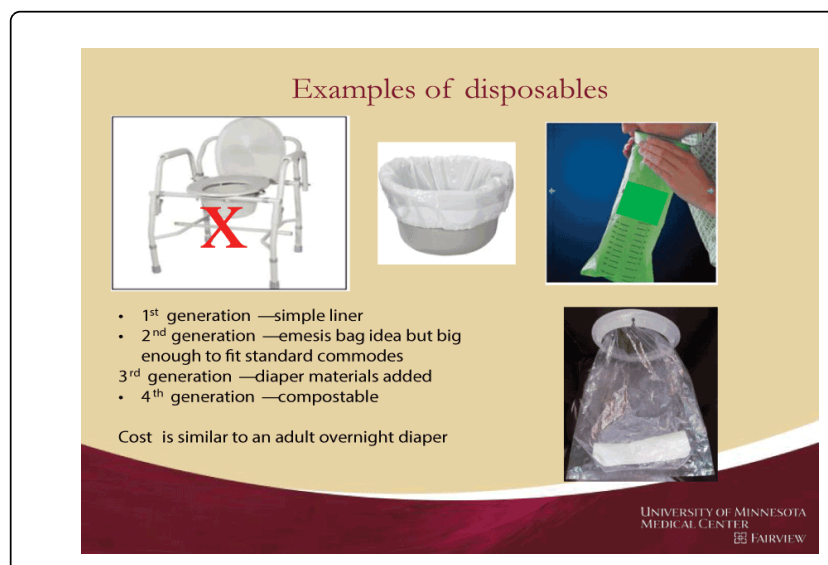

Figure 2: Example of Disposables. Delaney [7].

\section{Population}

At risk are all medical and surgical patients who must toilet at the bedside using commodes. Nursing staff may not realize the risks. Normalized deviation is the desensitization of at risk behaviors performed over time. If corners are cut over time, more staff will see and do. Shortcuts are taught to new staff and soon the wrong way becomes the right way. Just because everyone is doing it, doesn't mean it is right. While employees themselves are at highest risk for splash injuries because of longer GI pathogen exposure over time.

\section{Conclusion}

While more research is needed, the advantages of disposable bedside toileting equipment outweigh those of reusables. Current bedside toileting methods are associated with growing healthcare acquired infections. The standard of care for bedside toileting should 
Citation: Delaney MB. (2014) Declaring War on Clostridium difficile and other GI Pathogens: A Review of Disposable Commode Products. J Nurs Care 3: 195. doi:10.4172/2167-1168.1000195

Page 3 of 3

be disposables which better guarantees that clean equipment is used for patients at the bedside.

\section{References:}

1. Craig SA, Zich DK (2010) Gastroenteritis. In: Marx JA, ed. Rosen's Emergency Medicine. Philadelphia, PA: Mosby: 1200-1227.

2. Janka J, O'Grady NP (2009) Clostridium difficile infection: current perspectives. Curr Opin Crit Care 15: 149-153.

3. Alfa MJ, Olson N, Buelow-Smith L (2008) Simulated-use testing of bedpan and urinal washer disinfectors: evaluation of Clostridium difficile spore survival and cleaning efficacy. Am J Infect Control 36: 5-11.

4. Siani H, Cooper C, Maillard JY (2011) Efficacy of "sporicidal" wipes against Clostridium difficile. Am J Infect Control 39: 212-218.

5. DiDiodato G (2012) An alternative methodology for interpretation and reporting of hand hygiene compliance data. Am J Infect Control 40: 332-335.
6. Ganczak M1, Szych Z (2007) Surgical nurses and compliance with personal protective equipment. J Hosp Infect 66: 346-351.

7. Delaney MB (2013) Reducing Risks of Fecal Pathogen Exposure for ED Pts/Staff. J of Emerg Nrsg 40: 352-356.

8. Bryce E, Lamsdale A, Forrester L, Dempster L, Scharf S, et al. (2011) Bedpan washer disinfectors: an in-use evaluation of cleaning and disinfection. Am J Infect Control 39: 566-570.

9. Sobsey MD, Pillai SD (2009) Where future emerging pathogens will come from and what approaches can be used to find them, besides VFARs. J Water Health 7 Suppl 1: S75-93.

10. Sunenshine RH, Yee EL (2013) Infectious gastroenteritis. In: Jarvis WR, ed. Bennett \& Brachman's Hospital Infections. Philadelphia, PA: Lippincot: 561-566. 